\title{
Article \\ Improvement of Atmospheric Correction of Satellite Sentinel-3/OLCI Data for Oceanic Waters in Presence of Sargassum
}

\author{
Léa Schamberger ${ }^{1,2}$, Audrey Minghelli ${ }^{1,2, *} \mathbb{C}$, Malik Chami ${ }^{3}\left(\mathbb{C}\right.$ and François Steinmetz ${ }^{4}(\mathbb{C}$
}

check for

updates

Citation: Schamberger, L.; Minghelli,

A.; Chami, M.; Steinmetz, F.

Improvement of Atmospheric

Correction of Satellite Sentinel-3/

OLCI Data for Oceanic Waters in

Presence of Sargassum. Remote Sens.

2022, 14, 386. https://doi.org/

$10.3390 /$ rs 14020386

Academic Editors: Chung-Ru Ho,

Antony K. Liu and Xiaofeng Li

Received: 15 December 2021

Accepted: 12 January 2022

Published: 14 January 2022

Publisher's Note: MDPI stays neutral with regard to jurisdictional claims in published maps and institutional affiliations.

Copyright: (C) 2022 by the authors. Licensee MDPI, Basel, Switzerland. This article is an open access article distributed under the terms and conditions of the Creative Commons Attribution (CC BY) license (https:// creativecommons.org/licenses/by/ $4.0 /)$.
1 Laboratoire d'Informatique et Système (LIS), Université de Toulon, CNRS UMR 7020, F-83041 Toulon, France; lea-schamberger@etud.univ-tln.fr

2 Laboratoire d'Informatique et Système (LIS), Aix Marseille Université, F-13288 Marseille, France

3 Laboratoire Atmosphères Milieux Observations Spatiales (LATMOS), Sorbonne Université, CNRS-INSU, F-06304 Nice, France; malik.chami@upmc.fr

4 HYGEOS, Euratechnologies, 165 av. de Bretagne, F-59000 Lille, France; fs@hygeos.com

* Correspondence: audrey.minghelli@univ-tln.fr

\begin{abstract}
The invasive species of brown algae Sargassum gathers in large aggregations in the Caribbean Sea, and has done so especially over the last decade. These aggregations wash up on shores and decompose, leading to many socio-economic issues for the population and the coastal ecosystem. Satellite ocean color data sensors such as Sentinel-3/OLCI can be used to detect the presence of Sargassum and estimate its fractional coverage and biomass. The derivation of Sargassum presence and abundance from satellite ocean color data first requires atmospheric correction; however, the atmospheric correction procedure that is commonly used for oceanic waters needs to be adapted when dealing with the occurrence of Sargassum because the non-zero water reflectance in the near infrared band induced by Sargassum optical signature could lead to Sargassum being wrongly identified as aerosols. In this study, this difficulty is overcome by interpolating aerosol and sunglint reflectance between nearby Sargassum-free pixels. The proposed method relies on the local homogeneity of the aerosol reflectance between Sargassum and Sargassum-free areas. The performance of the adapted atmospheric correction algorithm over Sargassum areas is evaluated. The proposed method is demonstrated to result in more plausible aerosol and sunglint reflectances. A reduction of between $75 \%$ and $88 \%$ of pixels showing a negative water reflectance above $600 \mathrm{~nm}$ were noticed after the correction of the several images.
\end{abstract}

Keywords: Sargassum; atmospheric correction; aerosols; OLCI

\section{Introduction}

Sargassum is an algal invasive species originally found in the Sargasso Sea, which is located in the northwest of the Atlantic Ocean facing the State of Florida, USA between $20^{\circ}$ $\mathrm{N}$ and $35^{\circ} \mathrm{N}$. Since 2010, Sargassum has been found in large quantities elsewhere, typically in the south of the Caribbean Sea as far as Brazil, but also as far as West Africa. The spatial extent of Sargassum presence can possibly be explained by global climate changes, especially by the increase of oceanic water temperatures, by the modifications of hydrodynamical conditions and by the farming of deforested zones [1,2]. Once washed up on beaches, Sargassum decomposes, producing a gas impacting inhabitants' health, tourism and the coastal environment. Scientific researches are conducted to gain an understanding of the evolution of the Sargassum [3,4]. Remote sensing techniques can provide interesting information regarding standing stock forecasts in terms of spatial location, period of occurrence and abundance [5].

The presence of floating Sargassum can be detected using satellite imagery due to the increased water reflectance caused by Sargassum in the red and near infrared (NIR). 
$\mathrm{Hu}[6]$ has proposed the Floating Algae Index (FAI) applied to MODIS data to detect Sargassum aggregation using the red edge signal. However, the interpretation of such an index can be challenging due to the fact that Sargassum and cloud optical signature could both lead to high FAI values. Wang and Hu [7] modified the FAI to provide the Alternative Floating Algae Index (AFAI), which is less sensitive to the presence of cloud edges or thin clouds. Based on the AFAI, these authors were able to infer the fractional coverage of Sargassum in the Gulf of Mexico. Wang and Hu's method was adapted to ENVISAT/MERIS data by Gower et al. [8,9] through the Maximum Chlorophyll Index (MCI). The MCI was then adapted for the data acquired by the Ocean Land Color Imager (OLCI) sensor onboard the Sentinel-3 satellite platform. The current Sargassum reflectance indices use the top of atmosphere reflectance corrected for the Rayleigh scattering as inputs. This is because there is currently no reliable atmospheric correction that can be applied to derive the above water reflectance for the specific case of the presence of floating algae [9]. Although the aerosol correction may have a weak influence on the Algal Indices (AFAI and MCI) [6], which are based on spectral reflectance differences, such a correction remains necessary for applications that deal with the above water reflectance values, such as the derivation of Sargassum fractional coverage and the consideration of the immersion depth of the Sargassum aggregations. The performance of the atmospheric correction procedure is therefore of critical importance for providing relevant products related to Sargassum properties.

While the Rayleigh (i.e., molecular) atmospheric scattering component is well known in theory, the correction of top-of-atmosphere reflectance for the aerosol reflectance remains a challenging task because their optical properties cannot locally be predicted. Standard atmospheric correction methods over open ocean waters assume the water reflectance to be small in the near infrared (NIR) domain [10-12]. If the water reflectance is close to zero for such oceanic water, the top-of-atmosphere reflectance is mainly ascribed to the aerosol reflectance in addition to the Rayleigh scattering component. The derivation of the aerosol reflectance is carried out in the NIR domain based on the comparison between satellite measurements and reflectances simulated using various models of aerosol optical properties. Then, the aerosol models are used to estimate the aerosol reflectance in the visible domain. In the presence of Sargassum, such a common procedure cannot apply because Sargassum induce a strong water reflectance in the near infrared bands due to their optical signature in the red-edge part of the spectrum. Therefore, the NIR aerosol reflectance could be overestimated regarding pixels containing Sargassum (called "Sargassum pixels"), as compared with Sargassum-free areas, when using standard atmospheric correction procedures [13]. Other methods such as ACOLITE [14] can be considered to correct aerosol reflectance in the presence of algal blooms. In this paper, an extension of a given standard atmospheric correction method (POLYMER [15]) is proposed to derive the water reflectance from satellite data over oceanic waters containing Sargassum. The POLYMER method has the advantage of taking into account sunglint as well as absorbing inhomogeneous aerosols. The standard POLYMER algorithm has been successfully applied in the past to various satellite sensors, including ENVISAT/MERIS, Sentinel-2/MSI and Sentinel-3/OLCI data for Sargassum-free waters $[15,16]$.

This paper is organized as follows: the study area, the Sentinel-3/OLCI satellite data and the methodology used to adapt the standard atmospheric correction in the presence of Sargassum are outlined in Section 2. The evaluation of the performance of the Sargassum-dominated area detection and the benefits of the proposed atmospheric correction procedure are presented in Section 3. Finally, the consistency of the proposed atmospheric correction methodology is discussed in Section 4. 


\section{Materials and Methods}

\subsection{Study Area}

The study area is located in the Lesser Antilles Islands (Figure 1), off which an increasing amount of Sargassum aggregation has been observed in the Caribbean Sea since 2010.

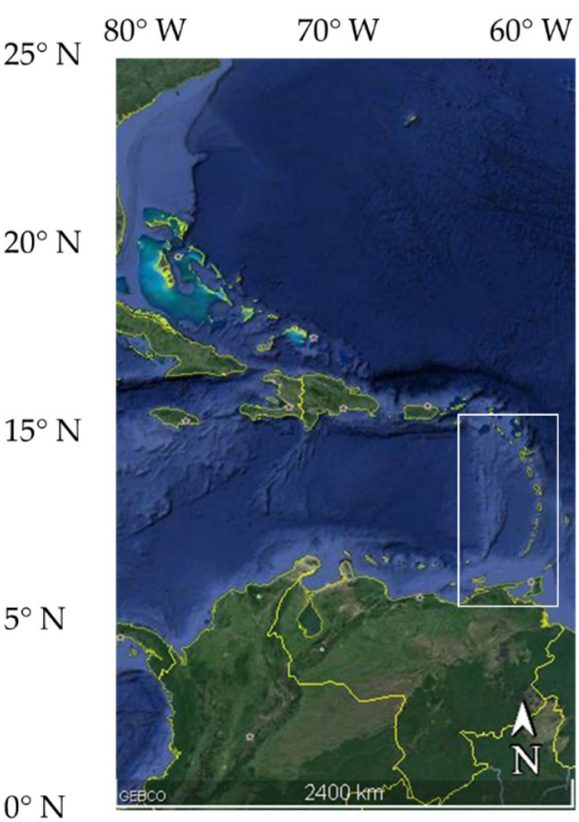

(a)

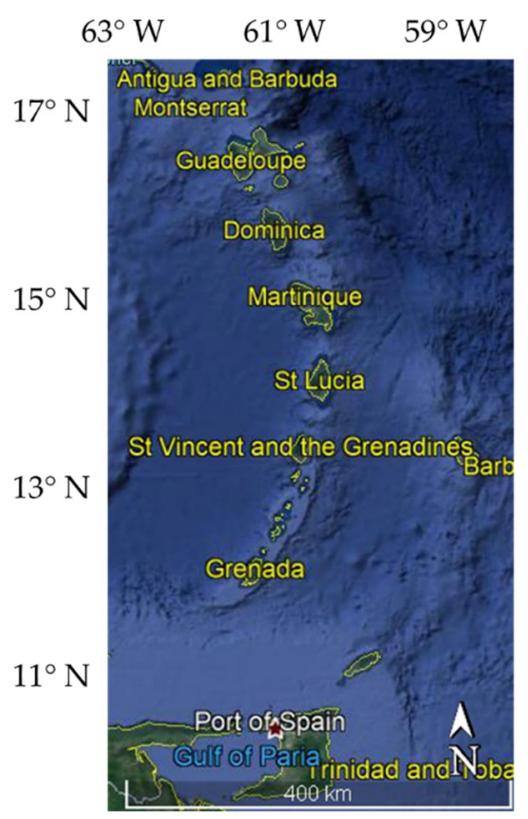

(b)

Figure 1. (a) Area of interest for the study: the Caribbean Sea; (b) Focus on the lesser Antilles Islands.

\subsection{Satellite Data}

The Ocean Land Color Instrument's (OLCI) satellite sensor, which is onboard the Sentinel-3 satellite platform, provides images at a spatial resolution of $300 \mathrm{~m}$ for 21 spectral bands from the visible to near infrared, namely from 400 to $1020 \mathrm{~nm}$. OLCI is highly appropriate for providing reliable ocean color observations thanks to its high radiometric sensitivity. Two satellite platforms were launched in 2016 and 2018, respectively, providing a 1-day temporal resolution [17].

Five Sentinel-3/OLCI images were analyzed for this study; they were acquired on 8 July 2017 13:00, 27 June 2018 14:24, 9 May 2020 14:00, 14 September 2020 14:20 and 28 December 2020 13:55. These images were selected because they exhibit numerous occurrences of Sargassum and were captured during different years and seasons. The Level-1 data product, namely the Top Of Atmosphere radiance, was downloaded from the Copernicus website [18]. Figure 2 shows the Red-Green-Blue (RGB) composite of the processed Sentinel-3/OLCI image acquired on 8 July 2017 13:00. 


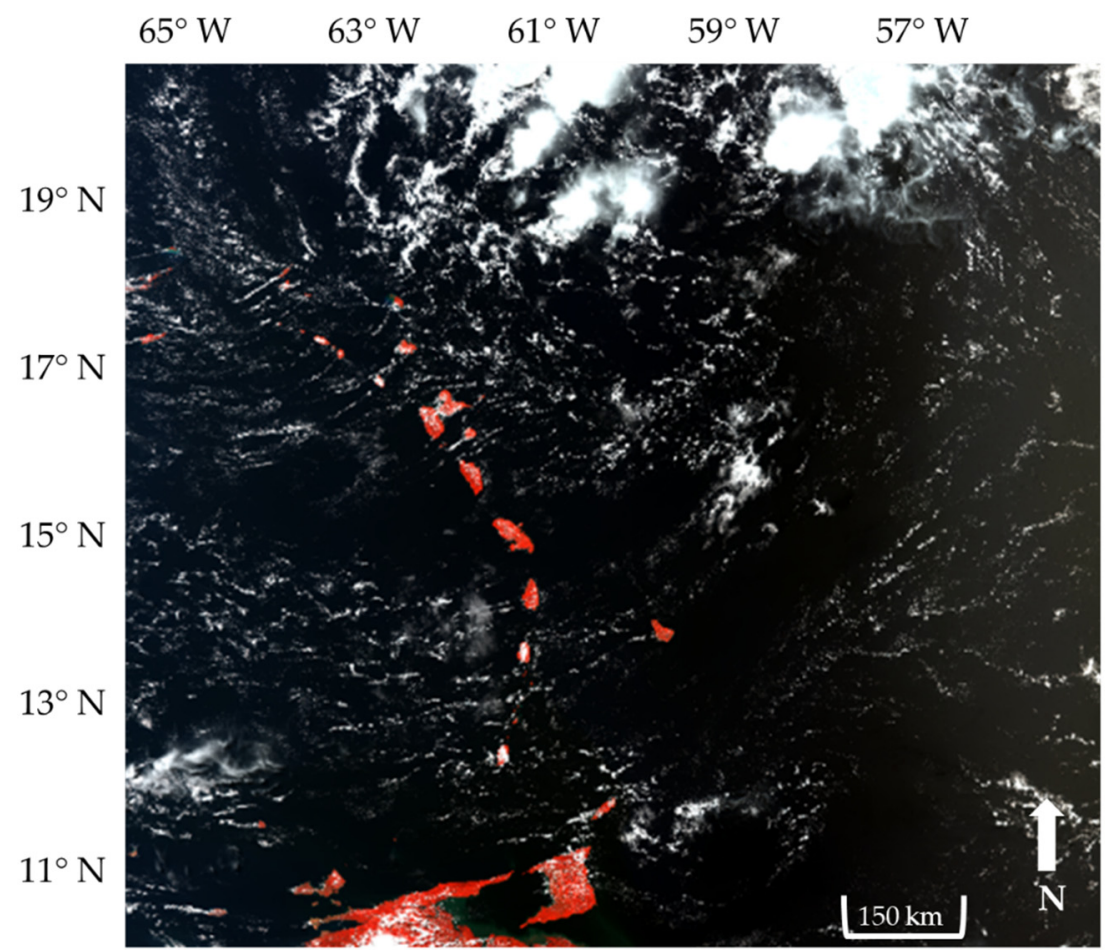

Figure 2. NIR-G-B composite image of the Sentinel-3/OLCI satellite data acquired on 8 July 2017 at 13:00.

\subsection{In Situ Data}

In situ measurements are important to correctly interpret satellite observations, especially to validate the proposed adjustment of the atmospheric correction procedure in the presence of Sargassum. Although in situ data were not collected for the current study, Ody et al. [18] were able to gather in situ data of Sargassum aggregations through two cruise campaigns in the western Atlantic Ocean between Brazil and the Caribbean Sea in the summer and autumn of 2017, which is the same period as the satellite image processed here. The above water reflectances were collected by Ody et al. using deck observations of Sargassum aggregations. Water reflectances were recorded for many Sargassum aggregations associated with their abundance (fractional coverage at the metric scale [12]). Although Ody et al.'s data cannot be rigorously used as a validation dataset in the current study, they will be used in Section 4 to discuss the benefits and the consistency of the proposed atmospheric correction method to correctly provide water reflectance in the presence of Sargassum.

\subsection{Methodology}

\subsubsection{Standard Procedure for Atmospheric Correction over Oceanic Waters}

The main steps of the atmospheric correction procedure that can typically be used above oceanic waters are reiterated here. The Level-1 satellite data consist of top-ofatmosphere radiance $\left(L_{\mathrm{TOA}}\right)$ that first need to be normalized by the cosine of the solar zenithal angle $(\theta s)$ and the extraterrestrial solar irradiance $(E s)$ to provide top-ofatmosphere reflectance (Equation (1)).

$$
\rho_{\mathrm{TOA}}(\lambda)=\frac{\pi L_{\mathrm{TOA}}(\lambda)}{\cos (\theta s) E s(\lambda)}
$$

$\rho_{\mathrm{TOA}}$ can be decomposed as a sum of various terms (Equation (2)):

$$
\rho_{\mathrm{TOA}}=t_{\mathrm{oz}} t_{\mathrm{NO} 2}\left(\rho_{\mathrm{mol}}+T \rho_{\mathrm{gli}}+\rho_{\mathrm{aer}}+\rho_{\text {coupl }}+t \rho_{\mathrm{w}}^{+}\right)
$$


where $t_{\mathrm{oz}}$ is the transmittance of the ozone and $t_{\mathrm{NO} 2}$ the transmittance of the nitrogen dioxide, $\rho_{\text {mol }}$ is the Rayleigh molecular scattering, $\rho_{\text {gli }}$ is the sunglint reflectance weighted by the direct transmittance $T, \rho_{\text {aer }}$ is the reflectance of the aerosols, $\rho_{\text {coupl }}$ accounts for the various coupling terms between the sunglint, the molecules and the aerosols, $t$ is the total (i.e., direct and diffuse) transmittance for atmospheric scattering and $\rho_{\mathrm{w}}^{+}$is the reflectance just above the air-water interface (i.e., water reflectance).

Some of the atmospheric contributions can be accurately predicted using either ancillary data or theoretical calculations. Those contributions consist of the ozone transmittance $t_{\mathrm{oz}}(\lambda)$, which is determined based on the total ozone concentration as provided by ECMWF data (European Centre for Medium-Range Weather Forecasts), and of the Rayleigh molecular scattering reflectance based on the atmospheric pressure at sea level. These inputs are stored in look-up tables to save computational time. The correction for the sunglint is performed using the ECMWF wind speed data that is derived from the sea surface roughness model by Cox and Munk (1954, [19]). The top-of-atmosphere reflectance can then be corrected by the ozone transmittance, the Rayleigh scattering effects and the sunglint reflectance. The resulting reflectance is hereafter referred to as $\rho^{\prime}$. The aerosol reflectance $\rho_{\text {aer }}$, the coupling term $\rho_{\text {coupl }}$, and the residue of sunglint reflectance that has not been totally corrected by Cox and Munk models are gathered under the notation $\rho_{\mathrm{ag}}$. Thus, the reflectance $\rho^{\prime}$ can be written based on Equation (2) as follows (Equation (3)):

$$
\rho^{\prime}(\lambda)=\rho_{\mathrm{ag}}(\lambda)+t(\lambda) \rho_{\mathrm{w}}^{+}(\lambda)
$$

If the water reflectance spectrum is assumed to be known, then $\rho_{a g}$ could be derived through the term $\rho^{\prime}-t \rho_{\mathrm{w}}^{+}$. The basic principle of the commonly used POLYMER algorithm [15] relies on the modeling of the atmosphere reflectance and the residual sunglint reflectances, namely the term $\rho_{\mathrm{ag}}$, as a polynomial function of $\lambda$ and $\rho_{\mathrm{mol}}$ to best represent the atmospheric signal even at high latitude (Equation (4)):

$$
\rho_{\mathrm{ag}}(\lambda) \approx t_{0}(\lambda) c_{0}+c_{1} \lambda^{-1}+c_{2} \rho_{\mathrm{mol}}
$$

where the coefficients $c_{0}, c_{1}$ and $c_{2}$ are estimated by the least square fitting of the satellite measurements and $t_{0}$ is the total transmittance due to the Rayleigh scattering. The water reflectance $\rho_{\mathrm{w}}^{+}$in the visible domain can then be derived as (Equation (5)).

$$
\rho_{\mathrm{w}}^{+}(\lambda)=\frac{\rho^{\prime}(\lambda)-\rho_{\mathrm{ag}}(\lambda)}{t(\lambda)}
$$

\subsubsection{Extension of the POLYMER Algorithm to Sargassum-Dominated Waters}

The spectral reflectance of pure Sargassum (Figure 3) is highly similar to land vegetation reflectance. The main feature is observed in the NIR bands where the reflectance strongly increases. A lower increase of the reflectance is observed in the green. Absorption properties of Sargassum can be observed through the decrease of the reflectance in the blue and the red bands. Although the proportion of Sargassum content in a given pixel is weak in the open ocean, typically lower than $5 \%$ as revealed from MODIS satellite data analysis using the monthly mean of the AFAI index [7], water reflectance remains high, especially in the NIR domain. As highlighted in Section 2.4.1, the aerosol reflectance is commonly derived from the reflectance measured in the NIR domain where the water reflectance is supposed to be negligible. Therefore, the influence of Sargassum on the standard atmospheric correction procedure could lead to overestimating the term $\rho_{\text {ag }}$ in the expression of $\rho^{\prime}$ (Equation (3)) because Sargassum optical signature is wrongly ascribed to an aerosol signal rather than an oceanic signal in the NIR part of the spectrum. 


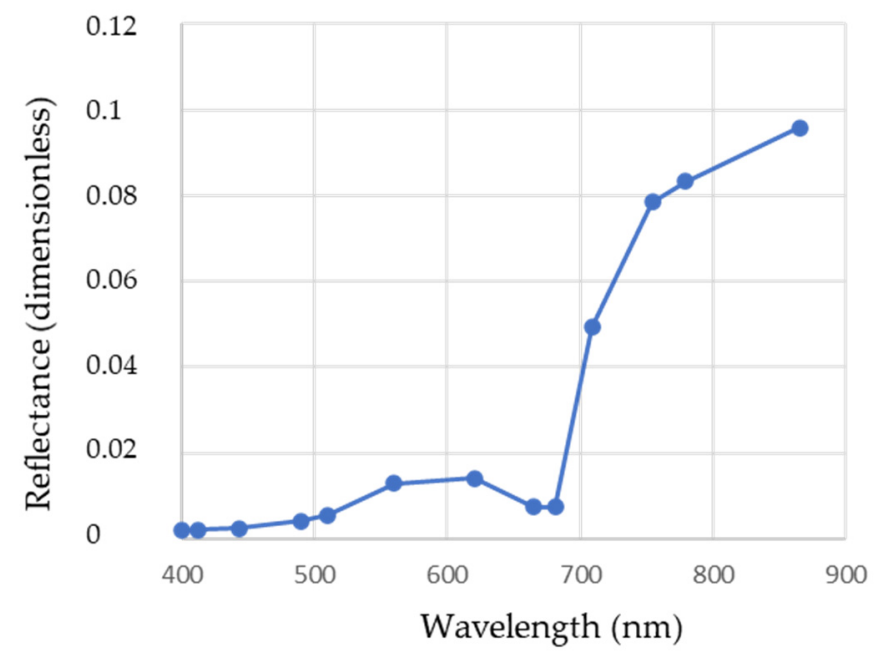

Figure 3. Spectral reflectance of pure Sargassum [20].

The spectral variation of $\rho^{\prime}, \rho_{\mathrm{ag}}$ and $\rho_{\mathrm{w}}^{+}$are shown in Figure $4 \mathrm{a}$ for a pixel containing only water (i.e., Sargassum-free pixel). The spectral decrease of $\rho_{\text {ag }}$ is consistent with the typical spectral decrease of aerosol reflectance with a wavelength in the red and near infrared spectral bands $[10,21]$. In the case of Sargassum-dominated water (Figure $4 \mathrm{~b}$ ), $\rho_{\mathrm{ag}}$ exhibits a minimum value at $500 \mathrm{~nm}$ and increases from $500 \mathrm{~nm}$ to $800 \mathrm{~nm}$, which is neither consistent with the usual spectral variation of aerosol reflectance, which typically varies as a decreasing power law, nor with the sunglint reflectance, which is fairly spectrally flat. Only a few types of aerosols, such as desert dust absorbing aerosols, might exhibit a steep increase in the reflectance with a wavelength from the blue to red/NIR range [22]. In any case, a minimum value of the aerosol spectral reflectance (here around $500 \mathrm{~nm}$ ), as observed in Figure $4 \mathrm{~b}$ (orange line), is not realistic from a physical point of view. The aerosol and sunglint effects are then theoretically overestimated for the case of Sargassum-dominated waters. The derived water reflectance $\rho_{\mathrm{w}}^{+}$thus shows negative values (Figure $4 \mathrm{~b}$ ), which is not realistic from a physical point of view. Consequently, Sargassum-dominated waters require a specifically dedicated atmospheric correction procedure.

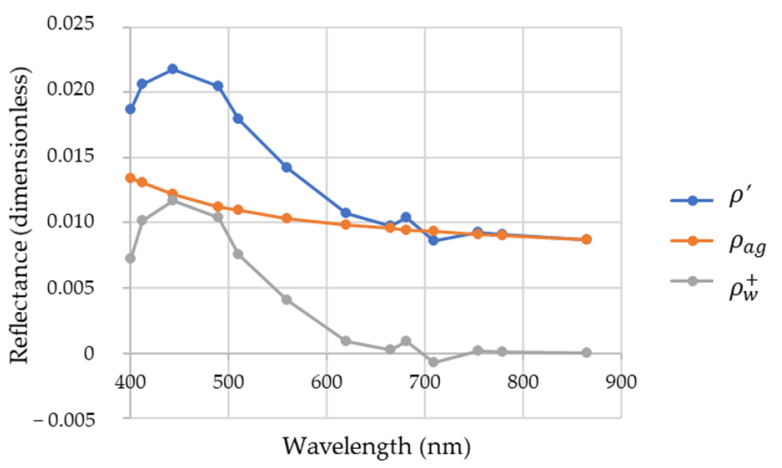

(a)

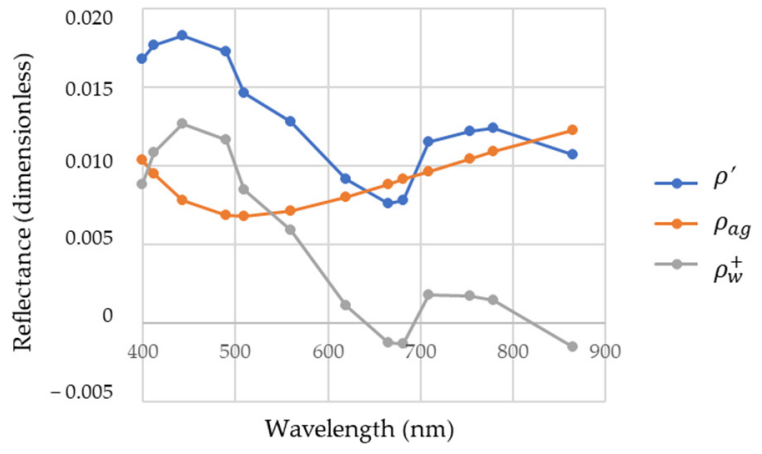

(b)

Figure 4. Reflectance corrected for Rayleigh molecular scattering $\left(\rho^{\prime}\right)$, reflectance of aerosol and sunglint $\left(\rho_{\mathrm{ag}}\right)$ and above water reflectance: (a) for a Sargassum-free area; (b) for a Sargassumdominated area.

Since the determination of aerosol and sunglint reflectance $\left(\rho_{\mathrm{ag}}\right)$ is challenging over Sargassum-dominated areas, we propose an extension of the POLYMER atmospheric cor-

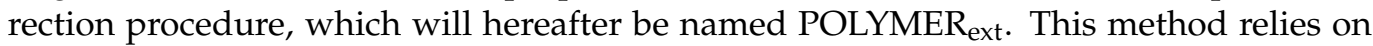
the idea of exploiting the value of $\rho_{\mathrm{ag}}$, which can be estimated over Sargassum-free waters 
using the standard method. The $\rho_{\text {ag }}$ reflectance over Sargassum-dominated areas is estimated by interpolating a $\rho_{\text {ag }}$ that has been derived using Sargassum-free waters located in the vicinity of the Sargassum waters. Then, the interpolated value of the aerosol and sunglint reflectance $\left(\rho_{\mathrm{ag}}\right)$ is subtracted from the top-of-atmosphere reflectance measured over the Sargassum-dominated areas. The underlying assumption of such a method is the consideration of a homogeneous spatial distribution of aerosols over the entire area (i.e., Sargassum-dominated area and its Sargassum-free neighborhood). To proceed in such a way, the Sargassum-dominated areas need to be first identified (i.e., flagged) and their inconsistent $\rho_{\text {ag }}$ values need to be removed. The method used to identify Sargassum dominated areas (or pixels), which is a necessary preliminary step prior to interpolating the aerosol-glint reflectance $\rho_{\mathrm{ag}}$, is described in the next section (Section 2.4.3). The method used to interpolate the Sargassum-free $\rho_{\mathrm{ag}}$ for Sargassum-dominated areas is the MatLab function called "fillmissing", which uses a linear interpolation between the closest $\rho_{\text {ag }}$ values that have been estimated for Sargassum-free areas. It should be noted that, even though the satellite data used in this study does not contain significant desert dust contamination, the applicability of the proposed method is mainly driven by the validity of the POLYMER method over Sargassum-free waters and thus is applicable to the case of the occurrence of moderate desert dust aerosols, especially since the red to NIR bands are not significantly affected by the aerosol absorption.

\subsubsection{Implementation of a Flag Dedicated to the Identification of Sargassum Pixels}

Clouds could lead to overestimation of the number of pixels containing Sargassum if they are wrongly identified, so cloud-contaminated pixels should be discarded from the analysis. The first step is then to flag pixels contaminated by clouds. The clouds are filtered using the method developed by Nordkvist et al. [23] for MODIS data because this method was found to be performant, including for the case of thin clouds. They demonstrated that pixels free of cloud, including thin cloud, can be identified using the Rayleigh-corrected topof-atmosphere reflectance acquired at bands $748 \mathrm{~nm}$ and $869 \mathrm{~nm}$ (respectively, $\lambda_{\mathrm{i}}$ and $\lambda_{\mathrm{j}}$ ). For the purpose of the current study, which is based on Sentinel-3/OLCI data, $\rho^{\prime}$ (Equation (3)) is used to identify the cloud-free pixels, including for thin cloud conditions. It should be noted that the proposed method does not detect the cloud shadows, but it should be highlighted that cloud shadows could be eliminated using an infrared sensor such as SLSTR following the method described by Fernandez-Moran et al. [24]. The criterion and threshold values used by Nordvist et al. to distinguish cloud-free pixels were revisited here to match with OLCI sensor spectral specifications as follows (Equation (6)):

$$
\left[\frac{\rho^{\prime}(865)}{t(865)}<0.0045 \text { OR } \frac{\frac{\rho^{\prime}(865)}{t(865)}}{\frac{\rho^{\prime}(754)}{t(754)}}<1.01\right] \text { AND }\left[\frac{\rho^{\prime}(865)}{t(865)}<0.06\right]
$$

Two methods are proposed to identify and detect the occurrence of Sargassum in this study. The first method, called "reflectance thresholding", is based on the fact that pixels containing Sargassum show an increase of the Rayleigh-corrected reflectance $\rho^{\prime}$ between the red and the NIR band (Figure 3). The criterion that has been established is based on the reflectance $\rho^{\prime}$ at bands $665 \mathrm{~nm}, 681 \mathrm{~nm}, 754 \mathrm{~nm}$ and $779 \mathrm{~nm}$ (Equation (7)).

$$
\max \left[\rho^{\prime}(665), \rho^{\prime}(681)\right]<\max \left[\rho^{\prime}(754), \rho^{\prime}(779)\right]
$$

The occurrence of Sargassum can also be detected using algal index thresholding. The MCI [8] is here used for the Rayleigh-corrected reflectance as follows (Equation (8)):

$$
M C I=\rho^{\prime}(709)-\left[\rho^{\prime}(681)+\left(\rho^{\prime}(754)-\rho^{\prime}(681)\right) \times \frac{709-681}{754-681}\right]
$$

The index value corresponding to Sargassum free waters, which is further called MCI background, is subtracted from the MCI to derive the MCI deviation $\delta M C I=M C I-$ 
$M C I_{\mathrm{bg}}$. The MCI background is determined using a median filter whose purpose is to reduce noise on the MCI. It should be noted that such a median filter is relevant when the large majority of pixels defining the filter are Sargassum-free pixels. Our tests showed that a filtering window of $167 \times 167$ pixels $(50 \mathrm{~km} \times 50 \mathrm{~km})$ is satisfactory for fulfilling such a condition. The histogram of $\delta M C I$ shows two modes (see Section 3.1.2): one can be identified as the Sargassum-free pixels and another one corresponding to higher $\delta M C I$ consists of the Sargassum-dominated pixels. A threshold value of $\delta M C I$ can be derived in between the two modes to detect a Sargassum-dominated areas from Sargassum-free areas.

\subsubsection{Flowchart of the Atmospheric Correction Algorithm Proposed for Sargassum Dominated Waters}

The flowchart of the methodology proposed for adjusting the POLYMER standard atmospheric correction for Sargassum-dominated areas (POLYMER ext $_{\text {) }}$ is shown in Figure 5. The Rayleigh molecular scattering correction of the top-of-atmosphere Level-1 reflectance is performed similarly over Sargassum-free and Sargassum-dominated areas. Thin clouds pixels are identified and masked. Then, the pixels containing Sargassum are identified and flagged. The aerosol and sunglint reflectances for the flagged Sargassum-dominated pixels are estimated through the interpolation of the derived aerosol and sunglint reflectances, as described in Section 2.4.2.

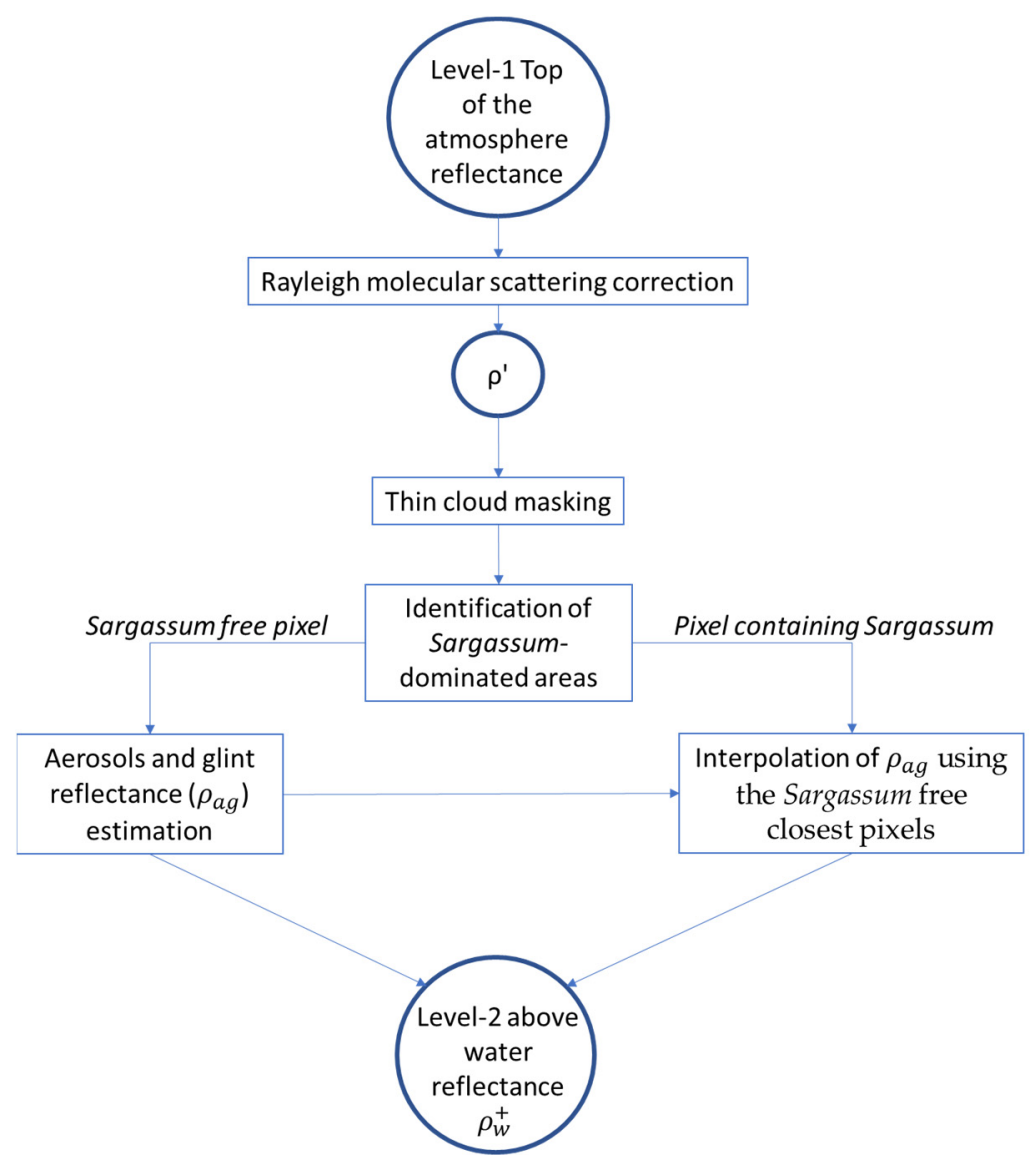

Figure 5. Flowchart of the POLYMER ext procedure to correct the top-of-atmosphere reflectance over Sargassum-dominated areas.

\section{Results}

3.1. Evaluation of the Performance of the Thin Cloud Masking and Sargassum Identification 3.1.1. Cloud Masking

Lands pixels are provided by the POLYMER algorithm. The thin cloud mask obtained using the method described in Section 2.4.3 is then used to eliminate cloud-contaminated 
pixels. The thin cloud mask applied to the OLCI reflectance data can be seen in Figure $6 \mathrm{~b}$ and can be compared with the NIR-G-B composite data acquired by Sentinel-3/OLCI on 8 July 2017 at 13:00 (Figure 6a). Pixels containing land, water (including Sargassum) and cloud are colored in green, blue and white, respectively.

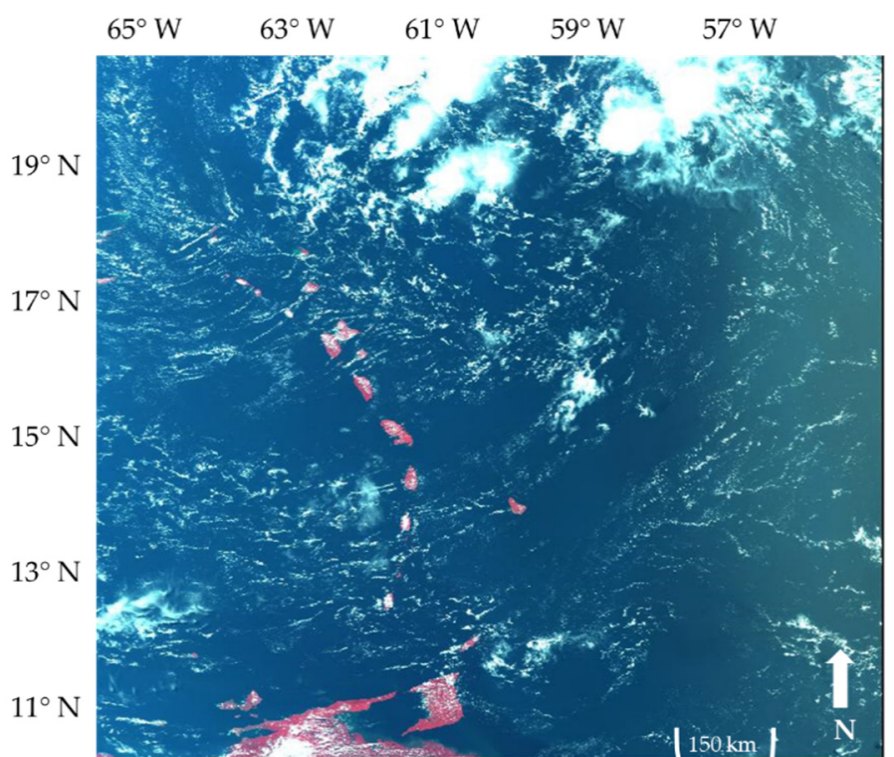

(a)

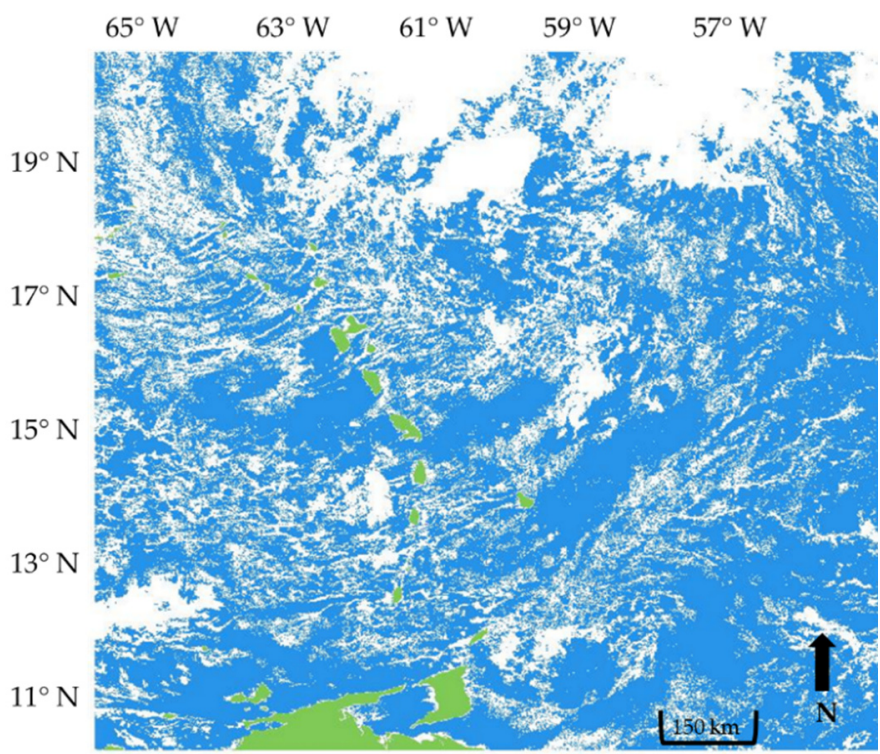

(b)

Figure 6. Data acquired by Sentinel-3/OLCI on 8 July 2017 at 13:00 (a) Level-1 data in NIR-G-B composite; (b) Water-land-cloud mask. Pixels containing land are in green, cloud-free pixels are in blue and cloud pixels are in white.

Figure 6 shows that the contribution of thin clouds, which are not observable on the NIR-G-B image (Figure 6a), is significant over the study area (Figure 6b).

\subsubsection{Identification of Sargassum Areas}

The identification of Sargassum-dominated areas is performed using a threshold value on the $\delta M C I$. For that purpose, the histograms of $\delta M C I$ values over entire Sentinel-3/OLCI scenes were analyzed. For each scene, its histogram is represented in Figure 7 . Those histograms have the same first significant peak. Three modes can be observed. The highest peak that is observed for the lowest values of $\delta M C I$ is mostly related to Sargassum-free pixels, which represent a large majority of pixels across the entire scene. The second and third modes that are observed for the highest values of $\delta M C I$ are mostly linked to the occurrence of Sargassum within the pixels. The difference between the two peaks could be due to the aggregation density. A threshold value could thus be determined between those two modes to distinguish pixels containing Sargassum from Sargassum-free pixels. The threshold-adopted value is the value of the threshold observed between the two modes, which has been decreased by $30 \%$ to make sure not to omit any Sargassum-dominated pixels (Figure 7). The threshold value of 0.002 is then determined (Figure 7). Such a threshold value has been estimated based on the histogram obtained for the image acquired on 8 July 2017 at 13:00 (in black in Figure 7). However, it was found to be a relevant value for several other acquisitions, namely Sentinel-3/OLCI data of 27 May 2018 14:24, 9 May 2020 14:00, 14 September 2020 14:20 and 28 December 2020 13:55. 


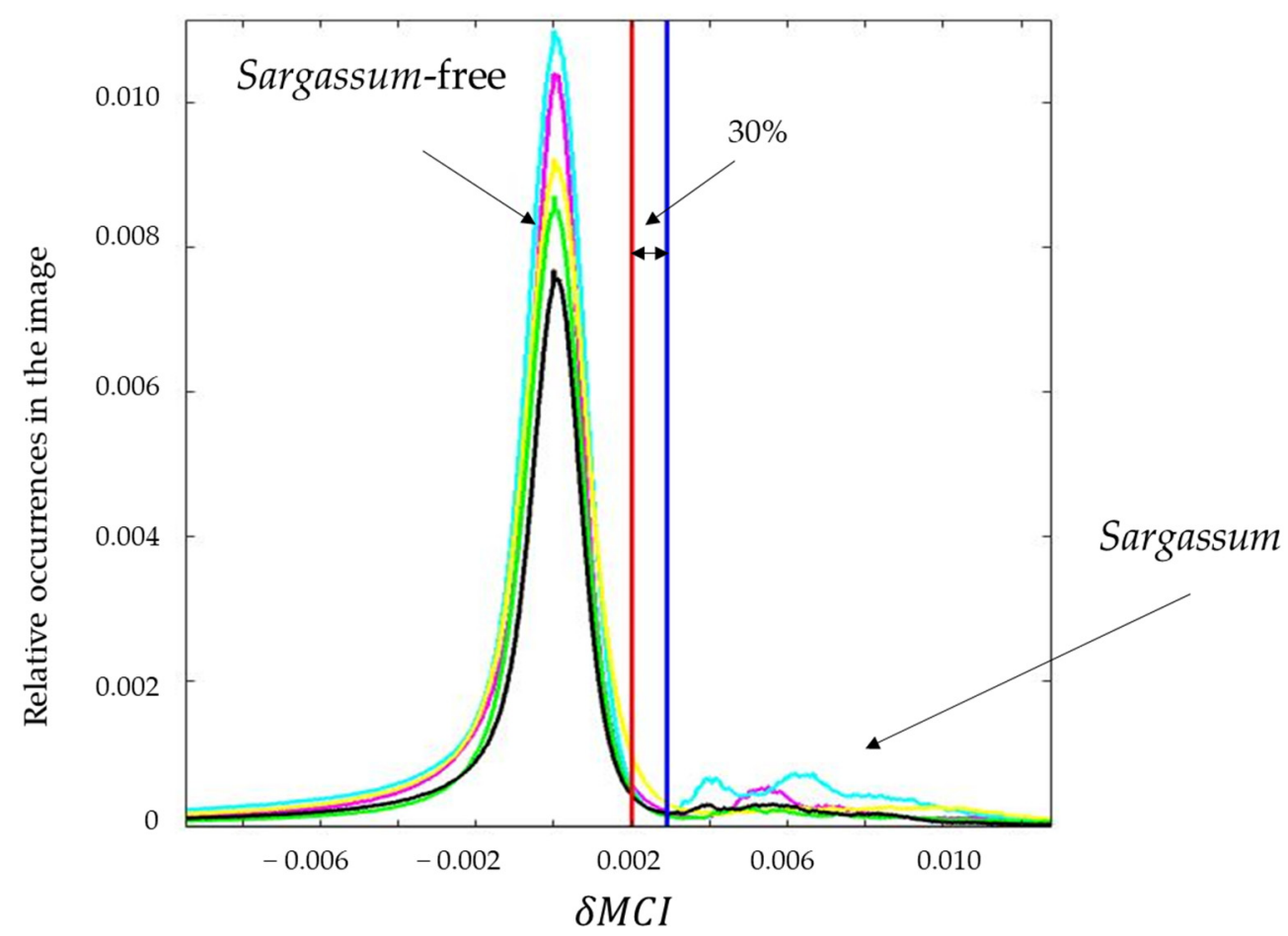

Figure 7. Histograms (number of occurrences) of $\delta M C I$ for each of the Sentinel-3/OLCI scenes. The histograms are represented for 8 July 2017 13:00 (black line), 27 May 2018 14:24 (yellow line), 9 May 2020 14:00 (green line), 14 September 2020 14:20 (magenta line) and 28 December 2020 13:55 (cyan line). The red vertical line shows the threshold value of 0.002 that has been adopted for this study. Such a value is $30 \%$ lower than the minimum value of $\delta M C I$ observed between the two modes (blue vertical line).

The comparison between the two approaches that have been proposed in Section 2.4.3 to detect the presence of Sargassum within the pixels, namely the reflectance thresholding approach and the $\delta M C I$ thresholding approach, is shown in Figure 8.

Sargassum aggregation edges are better detected in the whole scene when using the reflectance thresholding approach (red color in Figure 8b). However, some aggregations are largely underestimated on the right side of the image relative to the $\delta M C I$ thresholding approach, as observed in Figure 8c. The method using the $\delta M C I$ thresholding approach detects the main aggregations but leaves out many pixels on the edge of the Sargassum aggregation. In addition, a threshold value is likely to change depending on the image processed, thus leading to an overestimation or an underestimation of the Sargassumdominated pixels. On the one hand, omitting Sargassum-dominated pixels can be an issue for the interpolation of the aerosol and sunglint reflectance performed during the atmospheric correction procedure. On the other hand, an overestimation of Sargassumdominated pixels does not prevent the proposed atmospheric correction method. Then, a hybrid approach has been considered using both approaches to increase the performance of Sargassum detection. The Sargassum flags obtained using both the reflectance and $\delta M C I$ thresholding methods are merged to optimize the number of Sargassum aggregations detected over the entire scene. 


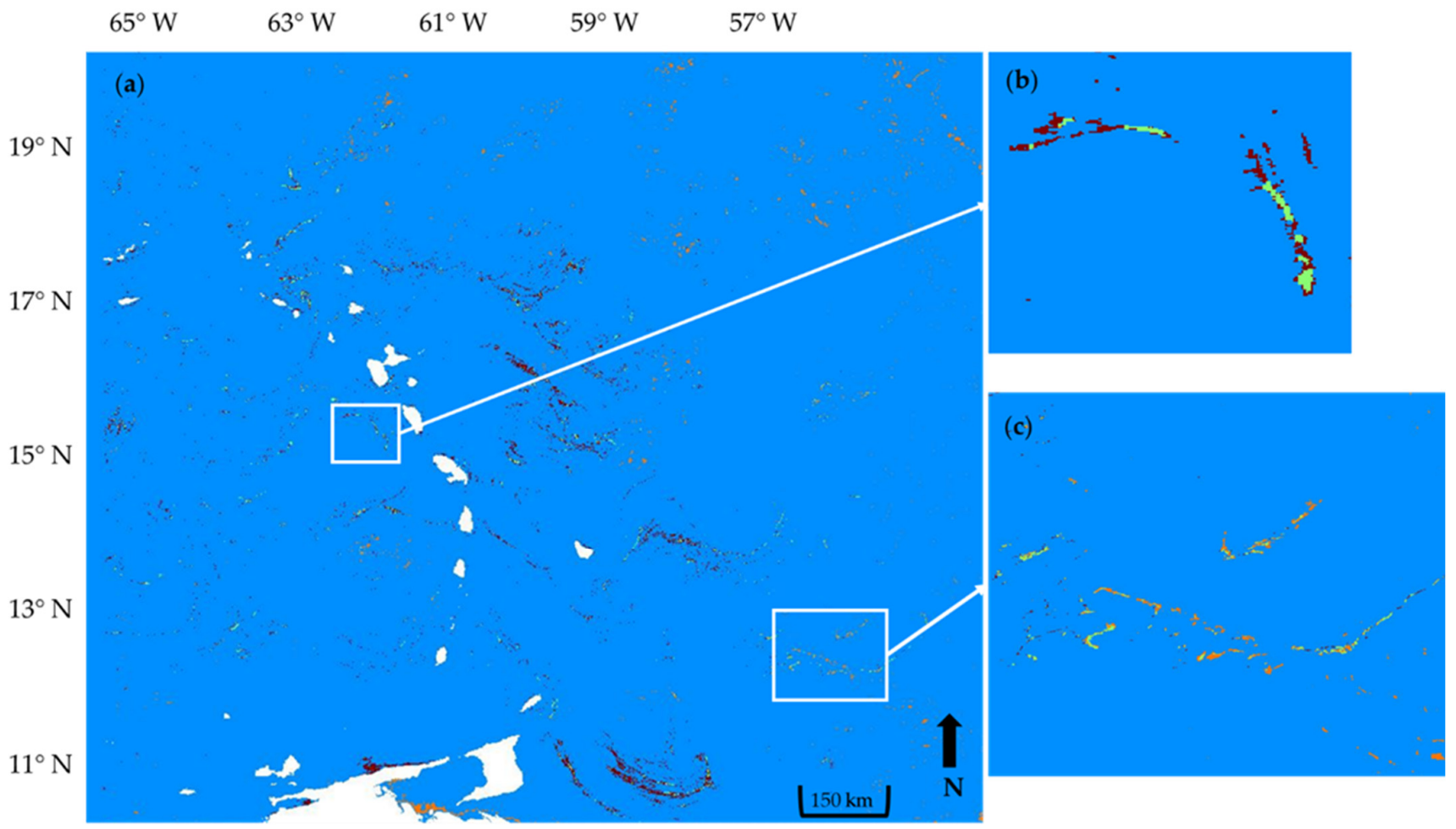

Figure 8. Sargassum identification using the two approaches proposed in this study (i.e., reflectance thresholding approach and $\delta \mathrm{MCI}$ thresholding approach) for the 8 July 2017 13:00 scene: (a) for the OLCI entire scene, (b) for a sub-area located westward of the Dominica Island and (c) for a sub-area located in the southeast of the scene. The results for each approach are presented using a different color: red color is used for the reflectance thresholding method and orange color is used for the $\delta M C I$ thresholding approach. If both approaches agree, pixels are colored in green. Land pixels are colored in white while Sargassum-free pixels (i.e., water only) are colored in blue. Clouds are also colored in blue to enhance the visibility of Sargassum areas.

\subsection{Benefit of the Proposed Atmospheric Correction Procedure Relative to a Standard Procedure}

The standard atmospheric correction procedure (POLYMER) is compared to the proposed method (POLYMER ext $_{\text {) }}$ to evaluate the improvement made for investigating the detection of Sargassum in oceanic waters (Figure 9).

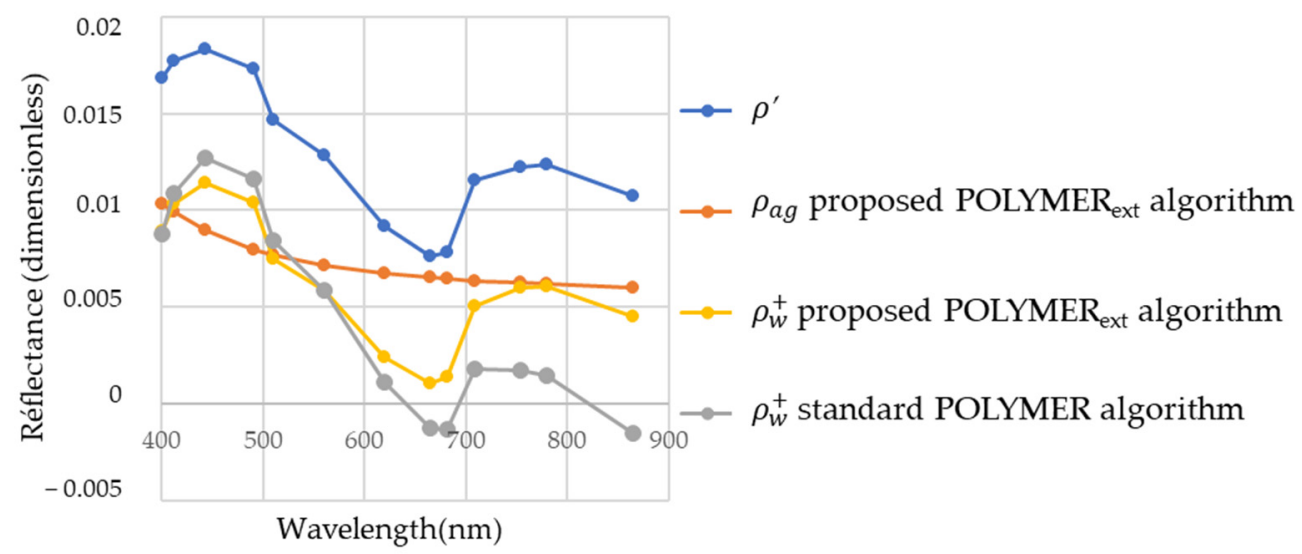

Figure 9. Reflectance corrected for the Rayleigh scattering $\left(\rho^{\prime}\right)$, reflectance of aerosol and sunglint $\left(\rho_{\mathrm{ag}}\right)$ and reflectance of above surface water for a pixel containing Sargassum derived for the case where (i) the standard POLYMER atmospheric correction procedure is used and (ii) the proposed POLYMER $_{\text {ext }}$ is used. 
The above water reflectances $\left(\rho_{\mathrm{w}}^{+}\right)$derived from both the standard and adapted POLYMER atmospheric correction algorithm are fairly similar in the spectral range $412 \mathrm{~nm}-$ $620 \mathrm{~nm}$. Beyond $620 \mathrm{~nm}$, significant discrepancies are observed between the two methods. The standard method provides negative values of $\rho_{\mathrm{W}}^{+}$(i.e., $<-0.001$ ) from $650 \mathrm{~nm}$ that are likely to be due to the overestimation of the aerosol and sunglint reflectance $\left(\rho_{\mathrm{ag}}\right)$ by the standard POLYMER algorithm as a result of the occurrence of Sargassum. The interpolation of $\rho_{\mathrm{ag}}$ derived for Sargassum-free pixels and applied to Sargassum pixels, as proposed by the POLYMER ext method, leads to a consistent spectral decrease of $\rho_{\text {ag }}$ over Sargassum areas (Figure 9). In addition, $\rho_{\mathrm{w}}^{+}$values remain positive and consistent with the spectral signature of Sargassum (i.e., increase of $\rho_{\mathrm{w}}^{+}$in the red-edge part of the spectrum, Figure 3).

The analysis of the entire scene reveals that approximately $85 \%$ of the negative values of $\rho_{\mathrm{w}}^{+}$between 620 and $681 \mathrm{~nm}$ derived by the standard approach have been corrected using the POLYMER ext algorithm. Similarly, the values of $\rho_{\mathrm{ag}}$ that showed a spectral increase with wavelength in the red/NIR bands when using the standard method have been replaced by spectrally consistent $\rho_{\text {ag }}$ values derived by the adapted approach. Figure 10 compares $\rho_{\mathrm{ag}}(754) / \rho_{\mathrm{ag}}(681)$ for Sargassum-dominated areas using POLYMER (Figure 10a) and POLYMER ext algorithms (Figure 10b). The values are mostly higher than 1 when using POLYMER, which means an increase of $\rho_{\mathrm{ag}}$ in the NIR domain (Figure 10a). The

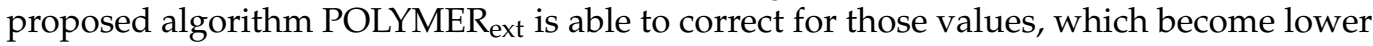
than 1 (Figure 10b). Several artefacts remain visible on the far east of the scene; they can be attributed to the strong impact of the glint in this area.

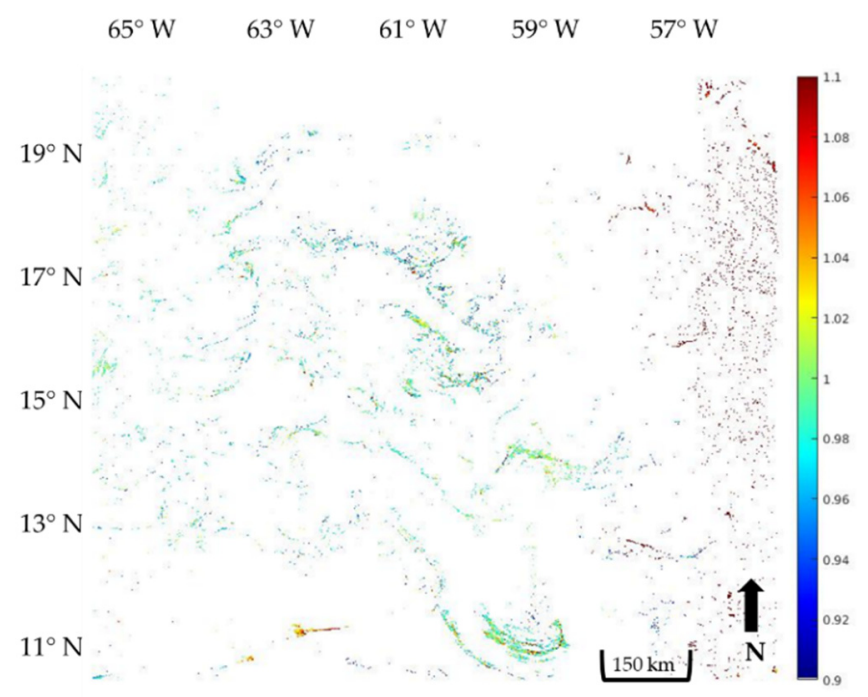

(a)

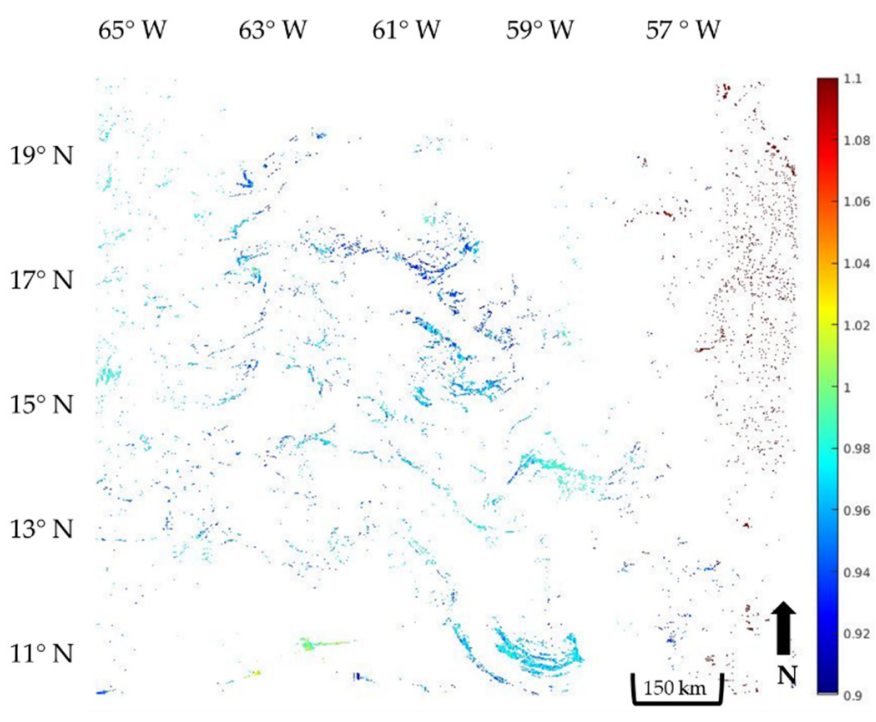

(b)

Figure 10. Spectral ratio of the aerosol and sunglint reflectance $\rho_{\mathrm{ag}}(754) / \rho_{\mathrm{ag}}(681)$ over Sargassumdominated areas in the scene acquired on 8 July 2017 13:00: (a) using POLYMER algorithm; (b) using

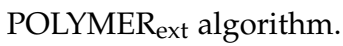

Therefore, the above water Level-2 reflectance derived for the adapted method is now optically relevant for improving the assessment of the Sargassum biomass using algal index.

Table 1 shows the percentage of negative reflectance values that has been corrected using POLYMER ext on Sargassum-dominated areas for the five scenes presented in Section 2.2. It is observed that more than $75 \%$ of the negative reflectance (between 620 and $681 \mathrm{~nm}$ )

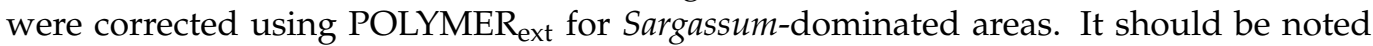
that the cloud coverage is more significant (about 50\%) on 27 May 2018 14:24 and on 14 September 2020 14:20, which could explain the lower efficiency of the algorithm for these two scenes. 
Table 1. Percentage of negative reflectance values corrected between (620 and $681 \mathrm{~nm}$ ) by using POLYMER $_{\text {ext }}$ on Sargassum-dominated areas.

\begin{tabular}{cc}
\hline Date of the Scene & $\begin{array}{c}\text { Percentage of Negative Reflectance Values } \\
\text { Corrected between (620 and } \mathbf{6 8 1} \mathbf{~ n m})\end{array}$ \\
\hline 8 July 2017 13:00 & $83 \%$ \\
27 May 2018 14:24 & $76 \%$ \\
9 May 2020 14:00 & $88 \%$ \\
14 September 2020 14:20 & $75 \%$ \\
28 December 2020 13:55 & $79 \%$ \\
\hline
\end{tabular}

\section{Discussion}

The extension of the POLYMER standard algorithm proposed in this study to perform atmospheric correction over Sargassum-dominated areas is important to enable the satellite data processing and monitoring of Sargassum variation with time and space from remote sensing techniques, especially when the above water reflectances are used rather than spectral reflectance differences. The POLYMER ext procedure relies on the assumption that the aerosol and sunglint reflectance $\rho_{\mathrm{ag}}$ is spatially homogeneous over the Sargassum areas relative to adjacent Sargassum-free areas. The relevance of such an assumption has been investigated. For that purpose, the standard atmospheric correction algorithm has been applied over a Sargassum-free area to provide $\rho_{\text {ag }}$ values (Figure 11a). Then, a rectangular sub-area within this area was considered as a test area. Since the area is Sargassum-free waters, $\rho_{\mathrm{ag}}$ inside such a test area can be considered as the reference $\rho_{\mathrm{ag}}$, hereafter referred to as $\rho_{\text {ag_ref. }}$ Then, in a second step, $\rho_{\text {ag }}$ over the test area was estimated as it could not be correctly retrieved using the standard POLYMER algorithm. Thus, the POLYMER ext method was used and $\rho_{\mathrm{ag}}$ from the surrounds of the test area was linearly interpolated in the test area, hereafter referred to as $\rho_{\text {ag_test }}$. The difference between $\rho_{\text {ag_test }}$ values and $\rho_{\text {ag_ref }}$ values are calculated to provide the Relative Root Mean Square Error (noted RRMSE). The relevance of the assumption made on the spatial homogeneity of $\rho_{\text {ag }}$ using these errors could be determined. Practically, an area was selected within the Sentinel-3/OLCI image acquired on 8 July 2017 at 13:00 without pixels containing clouds, without Sargassum and without anomalous spectral variation of $\rho_{\text {ag }}$. Then, a $300 \times 80$ pixel rectangle $(90 \mathrm{~km} \times$ $24 \mathrm{~km}$ ) was defined inside this area. It should be noted that the size of a $300 \times 80$ pixel rectangle is larger than the typical size of Sargassum aggregation [20]. The reflectance $\rho_{\mathrm{ag}}$ is interpolated for such $300 \times 80$ pixel area. A transect of the area for the 200th line is represented in Figure $11 \mathrm{~b}$, which shows $\rho_{\mathrm{ag}}, \rho_{\mathrm{ag} \_ \text {test }}$ and $\rho_{\mathrm{ag} \_ \text {ref }}$ at $560 \mathrm{~nm}$ for the study area. The mean relative RRMSE error between the interpolated $\rho_{\mathrm{ag}}$ values and the reference $\rho_{\text {ag }}$ values (i.e., Sargassum-free areas) varies between $0.09 \%$ and $11 \%$ inside the rectangle area. Such a low discrepancy confirms that the assumption made on the spatial local homogeneity of the aerosol is reliable.

The fill missing data method used could be improved because the interpolation is only made along lines and uses only two available values for the interpolation that can amplify uncertainty. An improved version of our approach might be to use the mean $\mathrm{x}$ and $\mathrm{y}$ of the first few pixels before the gap and the first few pixels after the gap for the interpolation, to do this both horizontally and vertically. Then, the shortest or nearest or the mean of the two interpolations weighted by gap length or distance is selected. 


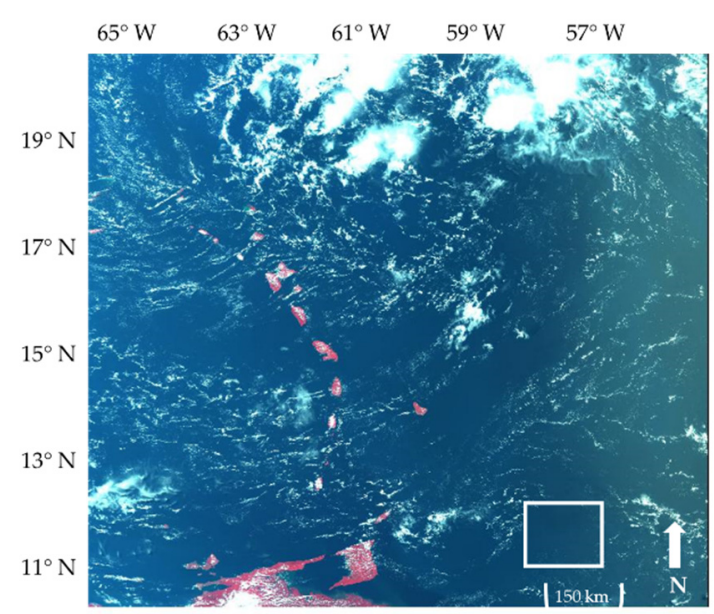

(a)

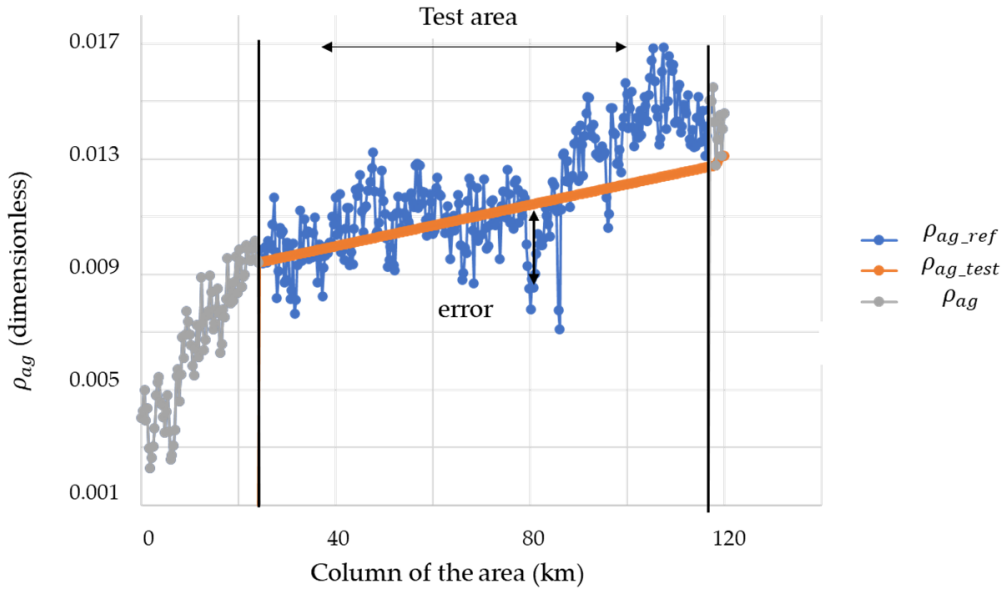

(b)

Figure 11. (a) Location of the test area (white rectangle); (b) Transect (200th line) of the Sargassum-free area for $\rho_{\text {ag_test }}(560 \mathrm{~nm})$ values and $\rho_{\text {ag }}(560 \mathrm{~nm})$ values.

The measurement of in situ data within Sargassum-dominated waters at the same date and location as a satellite data, called "match-up" data, is a challenging task because of the various scales of observation, typically a $300 \times 300 \mathrm{~m}^{2}$ area covered by the satellite observation versus a few meters covered by ship observations. However, the above water reflectance derived from the adapted atmospheric correction method was compared with the reflectance spectra measured during previous field experiments that occurred in 2017 in the western Atlantic Ocean (i.e., same study areas and time period as the current study) [18]. The typical water reflectances measured over Sargassum aggregation areas are shown in Figure 12a. Each reflectance spectrum corresponds to an abundance of Sargassum (in \%) determined based on water sample analysis. Even though the in situ data cannot be used as a rigorous validation of the proposed atmospheric correction method, they are helpful for analyzing the consistency of the estimated above water reflectance. Figure $12 \mathrm{~b}$ shows (i) two in situ measurements, (ii) the proposed POLYMER ext $_{\text {algorithm }}$ and (iii) the standard POLYMER algorithm for a pixel containing Sargassum. Such a figure highlights the inconsistency of the standard atmospheric correction procedure because of the negative reflectance values between $681 \mathrm{~nm}$ and $709 \mathrm{~nm}$. The water reflectance derived

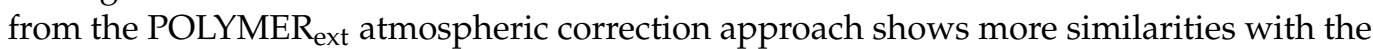
in situ reflectance measurements than the water reflectance derived from the standard algorithm, especially for the case of 5\% Sargassum abundance in the spectral range 681 $\mathrm{nm}-754 \mathrm{~nm}$. Such a comparison with the in situ data thus corroborates the relevance of the adjustments proposed in this study for the atmospheric correction procedure. It should also be highlighted that in situ sampling carried out across the Atlantic Ocean in previous studies did not reveal evidence of the occurrence of any other invasive species competitive with Sargassum [25-27]. Thus, although it might be theoretically possible, it is unlikely that other species could lead to the same red/NIR spectral features as Sargassum over our study area based on Ody et al.'s [20] in situ observations and other studies [25-27]. 


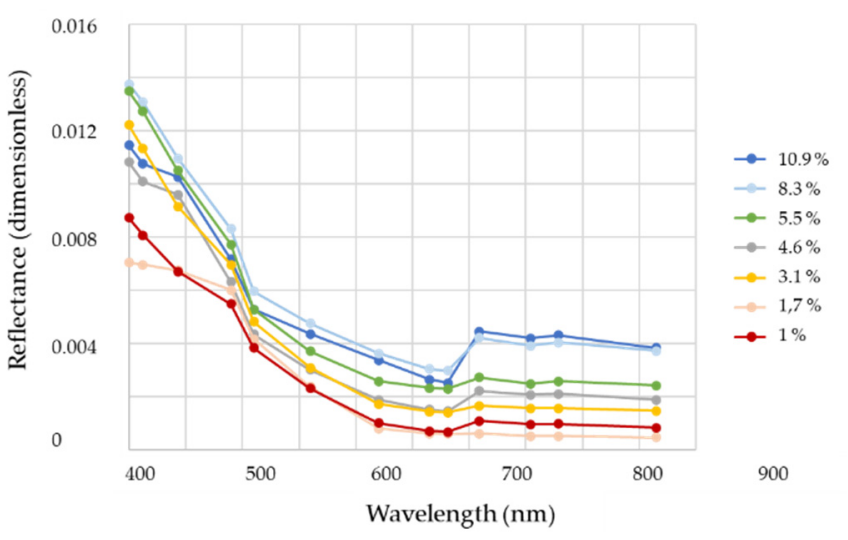

(a)

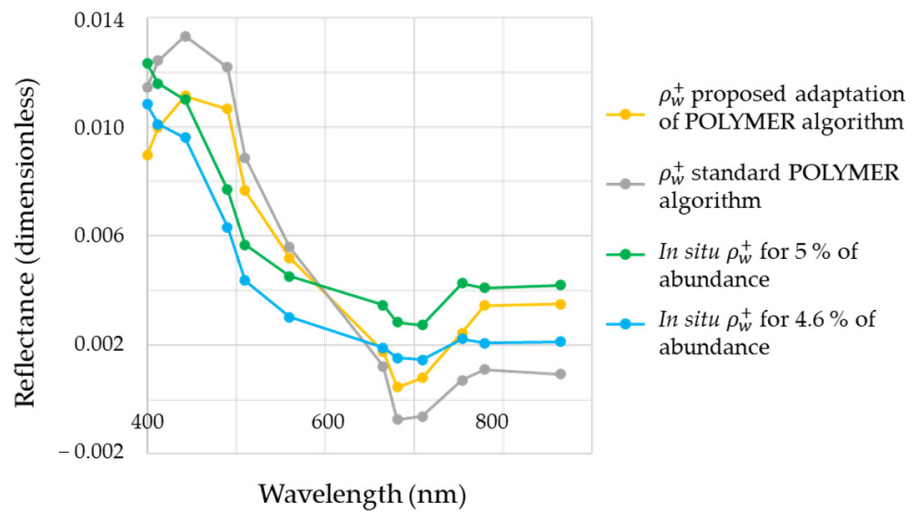

(b)

Figure 12. (a) Above water reflectance $\left(\rho_{\mathrm{w}}^{+}\right)$measured in situ in Sargassum-dominated areas in the Atlantic Ocean [20]. The different spectra correspond to different Sargassum abundances (\%); (b) comparison of the spectrum water reflectance measured in situ when the abundance is $4.6,4.8$ and $5 \%$ with the reflectance derived from the standard and adapted atmospheric correction procedure.

\section{Conclusions}

In this study, an adaptation of a standard atmospheric correction procedure, namely POLYMER, is proposed to correct the surface reflectance of pixels containing Sargassum. This method requires, first, a mask of thin clouds over the entire scene; the POLYMER standard procedure is only applied to the Sargassum-free area. Then, the aerosol reflectance over Sargassum-dominated areas is interpolated based on its value determined over the Sargassum-free area located in the vicinity of Sargassum waters. The proposed method assumes the spatial homogeneity of the aerosol reflectance, which has been shown as a relevant assumption. The proposed POLYMER ext procedure was successfully applied to Sentinel-3/OLCI data, for which the inconsistencies in the spectral variation of the aerosol reflectance (i.e., increase from visible to NIR bands) vanish. A reduction of between $75 \%$ and $88 \%$ of the pixels showing a negative water reflectance above $600 \mathrm{~nm}$ were noticed after the correction of the five images. The efficiency of the correction is fairly related to the cloud coverage. The more clouds, the less effective is the method. The comparison between the in situ data and the water reflectance derived over Sargassum areas based on the improved atmospheric correction corroborates the relevance of the proposed method. Therefore, relevant estimates of Sargassum variables such as biomass and fractional coverage could be further derived based on the methodology developed in this study. This method can also be applied to other satellite sensors, such as Aqua/MODIS, Terra/MODIS, SUOMINPP/VIIRS and Sentinel-2/MSI.

Author Contributions: Conceptualization, L.S., A.M. and M.C.; data curation, L.S.; formal analysis, M.C.; funding acquisition, A.M.; methodology, L.S., A.M. and M.C.; software, L.S.; supervision, A.M.; writing—original draft, L.S.; writing—review \& editing, A.M., M.C. and F.S. All authors have read and agreed to the published version of the manuscript.

Funding: This research was funded by l'Agence Nationale de la Recherche (France), grant number ANR-19-SARG-0007-07.

Institutional Review Board Statement: Not applicable.

Informed Consent Statement: Not applicable.

Data Availability Statement: Not applicable.

Conflicts of Interest: The authors declare no conflict of interest. 


\section{References}

1. Louime, C.; Fortune, J.; Gervais, G. Sargassum Invasion of Coastal Environments: A Growing Concern. Am. J. Environ. Sci. 2017, 13, 58-64. [CrossRef]

2. Jouanno, J.; Moquet, J.-S.; Berline, L.; Radenac, M.-H.; Santini, W.; Changeux, T.; Thibaut, T.; Podlejski, W.; Ménard, F.; Martinez, J.-M.; et al. Evolution of the Riverine Nutrient Export to the Tropical Atlantic over the Last 15 Years: Is There a Link with Sargassum Proliferation? Environ. Res. Lett. 2021, 16, 034042. [CrossRef]

3. Djakouré, S.; Araujo, M.; Hounsou-Gbo, A.; Noriega, C.; Bourlès, B. On the Potential Causes of the Recent Pelagic Sargassum Blooms Events in the Tropical North Atlantic Ocean. Biogeosci. Discuss. 2017, 1-20. [CrossRef]

4. Marx, U.C.; Roles, J.; Hankamer, B. Sargassum Blooms in the Atlantic Ocean-From a Burden to an Asset. Algal Res. 2021, 54, 102188. [CrossRef]

5. Maréchal, J.-P.; Hellio, C.; Hu, C. A Simple, Fast, and Reliable Method to Predict Sargassum Washing Ashore in the Lesser Antilles. Remote Sens. Appl. Soc. Environ. 2017, 5, 54-63. [CrossRef]

6. $\mathrm{Hu}, \mathrm{C}$. A Novel Ocean Color Index to Detect Floating Algae in the Global Oceans. Remote Sens. Environ. 2009, 113, 2118-2129. [CrossRef]

7. Wang, M.; Hu, C. Mapping and Quantifying Sargassum Distribution and Coverage in the Central West Atlantic Using MODIS Observations. Remote Sens. Environ. 2016, 183, 350-367. [CrossRef]

8. Gower, J.; Hu, C.; Borstad, G.; King, S. Ocean Color Satellites Show Extensive Lines of Floating Sargassum in the Gulf of Mexico. IEEE Trans. Geosci. Remote Sens. 2006, 44, 3619-3625. [CrossRef]

9. Hu, C.; Feng, L.; Hardy, R.F.; Hochberg, E.J. Spectral and Spatial Requirements of Remote Measurements of Pelagic Sargassum Macroalgae. Remote Sens. Environ. 2015, 167, 229-246. [CrossRef]

10. Gordon, H.R.; Wang, M. Retrieval of Water-Leaving Radiance and Aerosol Optical Thickness over the Oceans with SeaWiFS: A Preliminary Algorithm. Appl. Opt. 1994, 33, 443-452. [CrossRef] [PubMed]

11. Mobley, C.D.; Werdell, J.; Franz, B.; Ahmad, Z.; Bailey, S. Atmospheric Correction for Satellite Ocean Color Radiometry. 2016. Available online: https:/ / oceancolor.gsfc.nasa.gov/docs/technical/NASA-TM-2016-217551.pdf (accessed on 14 December 2021). [CrossRef]

12. Siegel, D.A.; Wang, M.; Maritorena, S.; Robinson, W. Atmospheric Correction of Satellite Ocean Color Imagery: The Black Pixel Assumption. Appl. Opt. 2000, 39, 3582-3591. [CrossRef]

13. Qi, L.; Hu, C.; Mikelsons, K.; Wang, M.; Lance, V.; Sun, S.; Barnes, B.B.; Zhao, J.; Van der Zande, D. In Search of Floating Algae and Other Organisms in Global Oceans and Lakes. Remote Sens. Environ. 2020, 239, 111659. [CrossRef]

14. Vanhellemont, Q.; Ruddick, K. Atmospheric Correction of Sentinel-3/OLCI Data for Mapping of Suspended Particulate Matter and Chlorophyll-a Concentration in Belgian Turbid Coastal Waters. Remote Sens. Environ. 2021, 256, 112284. [CrossRef]

15. Steinmetz, F.; Deschamps, P.-Y.; Ramon, D. Atmospheric Correction in Presence of Sun Glint: Application to MERIS. Opt. Express 2011, 19, 9783-9800. [CrossRef] [PubMed]

16. Steinmetz, F.; Ramon, D. Sentinel-2 MSI and Sentinel-3 OLCI Consistent Ocean Colour Products Using POLYMER. In Proceedings of the Remote Sensing of the Open and Coastal Ocean and Inland Waters, Honolulu, HI, USA, 30 October 2018; International Society for Optics and Photonics: Bellingham, WA, USA, 2018; Volume 10778, p. 107780.

17. Donlon, C.; Berruti, B.; Buongiorno, A.; Ferreira, M.-H.; Féménias, P.; Frerick, J.; Goryl, P.; Klein, U.; Laur, H.; Mavrocordatos, C.; et al. The Global Monitoring for Environment and Security (GMES) Sentinel-3 Mission. Remote Sens. Environ. 2012, 120, 37-57. [CrossRef]

18. Copernicus Open Access Hub Website. Available online: https://scihub.copernicus.eu/ (accessed on 5 October 2021).

19. Cox, C.; Munk, W. Measurement of the Roughness of the Sea Surface from Photographs of the Sun's Glitter. Josa 1954, 44, 838-850. [CrossRef]

20. Ody, A.; Thibaut, T.; Berline, L.; Changeux, T.; André, J.-M.; Chevalier, C.; Blanfuné, A.; Blanchot, J.; Ruitton, S.; Stiger-Pouvreau, V.; et al. From In Situ to Satellite Observations of Pelagic Sargassum Distribution and Aggregation in the Tropical North Atlantic Ocean. PLoS ONE 2019, 14, e0222584. [CrossRef]

21. Scheirer, R.; Dybbroe, A.; Raspaud, M. A General Approach to Enhance Short Wave Satellite Imagery by Removing Background Atmospheric Effects. Remote Sens. 2018, 10, 560. [CrossRef]

22. Tanré, D.; Kaufman, Y.; Holben, B.N.; Chatenet, B.; Karnieli, A.; Lavenu, F.; Blarel, L.; Dubovik, O.; Remer, L.; Smirnov, A. Climatology of Dust Aerosol Size Distribution and Optical Properties Derived from Remotely Sensed Data in the Solar Spectrum. J. Geophys. Res. Atmos. 2001, 106, 18205-18217. [CrossRef]

23. Nordkvist, K.; Loisel, H.; Gaurier, L.D. Cloud Masking of SeaWiFS Images over Coastal Waters Using Spectral Variability. Opt. Express 2009, 17, 12246-12258. [CrossRef]

24. Fernandez-Moran, R.; Gómez-Chova, L.; Alonso, L.; Mateo-García, G.; López-Puigdollers, D. Towards a Novel Approach for Sentinel-3 Synergistic OLCI/SLSTR Cloud and Cloud Shadow Detection Based on Stereo Cloud-Top Height Estimation. ISPRS J. Photogramm. Remote Sens. 2021, 181, 238-253. [CrossRef]

25. Schell, J.M.; Goodwin, D.S.; Siuda, A.N. Recent Sargassum Inundation Events in the Caribbean: Shipboard Observations Reveal Dominance of a Previously Rare Form. Oceanography 2015, 28, 8-11. [CrossRef] 
26. Dibner, S.; Martin, L.; Thibaut, T.; Aurelle, D.; Blanfuné, A.; Whittaker, K.; Cooney, L.; Schell, J.M.; Goodwin, D.S.; Siuda, A.N. Consistent Genetic Divergence Observed among Pelagic Sargassum Morphotypes in the Western North Atlantic. Mar. Ecol. 2021, e12691. [CrossRef]

27. Martin, L.M.; Taylor, M.; Huston, G.; Goodwin, D.S.; Schell, J.M.; Siuda, A.N. Pelagic Sargassum Morphotypes Support Different Rafting Motile Epifauna Communities. Mar. Biol. 2021, 168, 115. [CrossRef] 